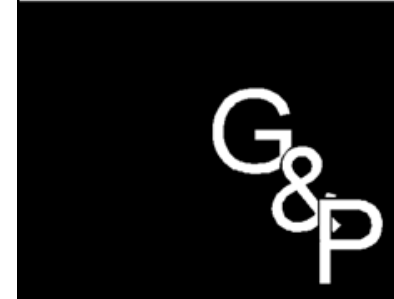

GESTÃO

$\&$

PRODUÇÃO

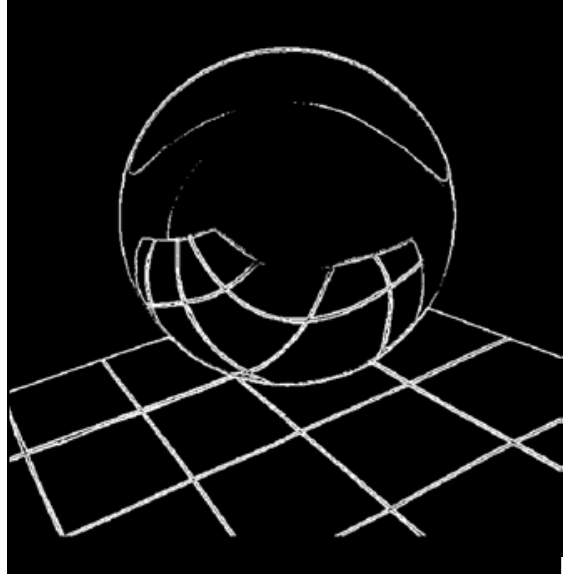

v.6, n.3, p. 185-200, dez. 1999

\section{MUDANÇAS INSTITUCIONAIS E DESEMPENHO DA PRODUÇÃO DE MILHO E SOJA NO BRASIL E NAARGENTINA}

\author{
Eduardo Luis Leão de Sousa \\ Maria Sylvia Macchione Saes \\ Rubens Nunes \\ FIPE/USP \\ E-mails: ellsousa@carpa.ciagri.usp.br, \\ msmsaes@usp.br, rnune@mandic.com.br
}

\title{
Resumo
}

As mudanças no ambiente institucionais e seus efeitos sobre o desempenho recente da produção de milho e soja no Brasil e Argentina são os objetivos deste artigo, que tem como referencial teórico a Nova Economia das Instituições. Importantes diferenças marcam o desempenho da produção de grão nestes países, apesar do Brasil e Argentina terem seguido o mesmo modelo de desenvolvimento baseado no processo de substituição de importação e economia fechada. Observa-se também que além das condições edáfo-climáticas que trazem uma vantagem inicial para a produção de grãos na Argentina, de uma forma geral, este país, em função da sua menor população e menor absorção interna de produtos, sempre teve uma maior inserção no mercado internacional.

Palavras-chave: grãos: milho e soja, mudanças institucionais, organizações, instituições, estratégias, competitivas, substituição de importação, orientação externa, política agrícola.

\section{Introdução}

$\mathrm{O}$ sistemas produtivos no Brasil e na Argentina têm sido fortemente afetados pelas mudanças no ambiente institucional que estão ocorrendo desde o final dos anos 80. Em diversos setores da economia, a abertura e a formação do Mercado Comum do Sul, que foram seguidas de profundas reformas econômicas, têm levado a uma forte reestruturação produtiva com alterações significativas das posições dos agentes produtivos. No caso dos 
sistemas do milho e da soja, não poderia ser diferente, particularmente considerando sua importância para a economia desses dois países.

Juntos o Brasil e a Argentina respondem por $30 \%$ da soja e 9\% do milho produzidos no mundo. A Argentina é o segundo maior exportador mundial de milho e o terceiro de soja, enquanto o Brasil é o segundo de soja.

Importantes diferenças, entretanto, marcam o desempenho da produção de grãos nesses dois países. Além do fator edáfo-climático que traz vantagens iniciais para a produção de grãos na Argentina, de uma forma geral, este país, em função da sua menor população e menor absorção interna de produtos, sempre teve uma maior inserção no mercado internacional.

Estudar as mudanças do ambiente institucional em um contexto de integração regional e os seus reflexos sobre o desempenho recente da produção de soja e milho no Brasil e Argentina é o objetivo deste trabalho, que está dividido em quatro seções, além desta introdução. A seção dois caracteriza brevemente o enfoque institucionalista assumido como referencial teórico para a análise comparativa. A seguir, na seção três, são descritas as principais mudanças nas regras do jogo nos sistemas agroindustriais da soja e do milho. A quarta seção compara o desempenho desses sistemas. Encerrando o texto, a seção cinco traz breves considerações finais.

\section{Enfoque Teórico}

A experiência do Brasil e da Argentina mostra que os dois países tiveram trajetórias econômicas muito similares. Ambos passaram por modelos de desenvolvimento ligados à exportação de produtos primários e à produção de substitutos de importação. Na etapa que corresponde à substituição de importações (IS), os países adotaram estratégias de proteção das indústrias locais contra a ameaça de perturbações externas. No final dos anos 80 , com o esgotamento da etapa IS, associadas em grande parte ao escasseamento de oportunidades de investimento dentro do paradigma tecnológico vigente, tanto a Argentina como o Brasil voltaram suas economias para fora, adotando o modelo de orientação externa (OE), como também passaram a empreender uma política de integração regional (IR).

Apesar das similaridades nas trajetórias das economias argentina e brasileira, o desenvolvimento das duas economias, e em particular do setor ligado ao agribusiness, apresentam resultados distintos. Boa parte dessas diferenças podem ser atribuídas às condições dadas em cada um dos países, tais como características edáfoclimática, que implicam em distintas vantagens comparativas, e importância do mercado consumidor que levaram a constituição de diferentes instituições na busca de soluções específicas.

O Brasil é um país continental com uma grande população. Significativa parcela da produção doméstica é destinada a abastecer o mercado consumidor. Por vezes, o abastecimento é também garantido pelas importações. A Argentina é exportadora líquida de produtos agrícolas e por isso mesmo antes de entrar na etapa OE o seu mercado já se encontrava bastante aberto para o exterior.

O Quadro 1 apresenta algumas características básicas das economias dos dois países mostrando as assimetrias entre eles. O PIB Argentino representa $40 \%$ do PIB do Brasil. Já o PIB per capita da Argentina é $200 \%$ superior ao brasileiro. A população rural no Brasil é comparativamente maior que a da Argentina e os impostos sobre o valor agregado e os juros no Brasil são superiores. A Argentina possui uma malha ferroviária maior que a brasileira.

A Figura 1 apresenta um esquema integrado das relações entre condições básicas da economia, mudanças institucionais, ambiente competitivo e estratégias das organizações. A etapa $\mathrm{OE}$ e de constituição da IR implica a criação de novas regras institucionais (queda de tarifas, desregulamentação, política agrícola menos intervencionista e reforma tributária). Tais regras estão, entretanto, condicionadas pelas condições 
Quadro 1 - Indicadores econômicos: Brasil e Argentina. Fonte: Gazeta Mercantil Latino Americana (vários números).

\begin{tabular}{|c|c|c|}
\hline Indicadores Econômicos & Brasil & Argentina \\
\hline - PIB (1998) (US\$ bilhões) & 786,21 & 322,28 \\
\hline - População (em milhões) & 166,57 & 34,00 \\
\hline - População Agrícola /não agrícola & $21,8 \%$ & $12,1 \%$ \\
\hline - PIB per capita (US\$ mil) & 4,72 & 9,47 \\
\hline - Desemprego (\% da PEA) & 7,7 (jan/99) & 12,4 (out/98) \\
\hline - $\mathrm{PIB} \mathrm{Ag} / \mathrm{PIB} *$ & $14,3 \%$ & $7,4 \%$ \\
\hline - Juros (\% ao ano) & $43,3(\mathrm{mar} / 99)$ & $8,9(\mathrm{mar} / 99)$ \\
\hline - Preço ao consumidor (\% em 12 meses) & $6,48(\mathrm{fev} / 99)$ & 0,47 (fev/99) \\
\hline - Alíquota máxima do Imposto sobre Valor Agregado** & 29,8 & 27 \\
\hline $\begin{array}{r}\text { - Infra-estrutura - área total } \\
\text { Rodovia } \\
\text { Ferrovia }\end{array}$ & $\begin{array}{r}8,512 \text { milhões } \mathrm{km}^{2} \\
1,6 \text { milhão km } \\
29,3 \text { mil km }\end{array}$ & $\begin{array}{r}2,767 \text { milhões km² } \\
211 \mathrm{mil} \mathrm{km} \\
35,7 \mathrm{mil} \mathrm{km}\end{array}$ \\
\hline
\end{tabular}

* Agrícola e Pecuária

** No Brasil é o conjunto ICMS/IPI.

básicas de cada sociedade (população, renda per capita, infra-estrutura, regime político etc.).

O novo paradigma institucional acarreta mudanças no ambiente competitivo. A queda de barreira tarifárias e a desregulamentação torna o mercado interno menos protegido, implicando o aumento da concorrência. A abertura também coloca em xeque política de garantia de preços mínimos e induz reformas tributárias para aumentar a competitividade do setor produtivo interno. A abertura de mercado traz para dentro do país tendências de mercado mundial, no qual a customização e valorização de atributos específicos passam, junto com preço, a ser importantes variáveis de competição.

Tanto o ambiente institucional como o competitivo apresentam-se como restrições ou conjunto de oportunidades para o desenvolvimento das organizações. $\mathrm{O}$ ambiente institucional fornece o conjunto de regras que determinam as estratégias das organizações (enfoque em custos, diferenciação ou segmentação) e as formas organizacionais para suportar tais estratégias (mercado, contratos ou hierarquia). São as estratégias das organizações que vão determinar o desempenho no mercado interno ( $\%$ das vendas sobre o total consumido) e no internacional ( $\%$ das vendas sobre o total exportado).

Representadas pelas linhas tracejadas, observa-se um efeito de feed-back entre instituições, organizações e condições básicas, que produzem a dependência das decisões tomadas pelas organizações em um certo momento em relação às tomadas anteriormente. $\mathrm{O}$ próprio campo das escolhas e os prêmios associados a cada escolha possível dependem da trajetória adotada (path dependence), que, por vezes, explica a perpetuação de trajetórias que levam a ineficiência em termos de desempenho econômico. Uma instituição ineficiente "pode persistir porque os custos de transação dos mercados políticos e econômicos, juntamente com os modelos subjetivos dos atores, não induzem os sistemas econômicos a caminharem em direção de resultados mais eficientes" (NORTH apud FARINA et al., 1997:69).

Os objetivos dos reguladores podem não coincidir com a busca de competitividade 


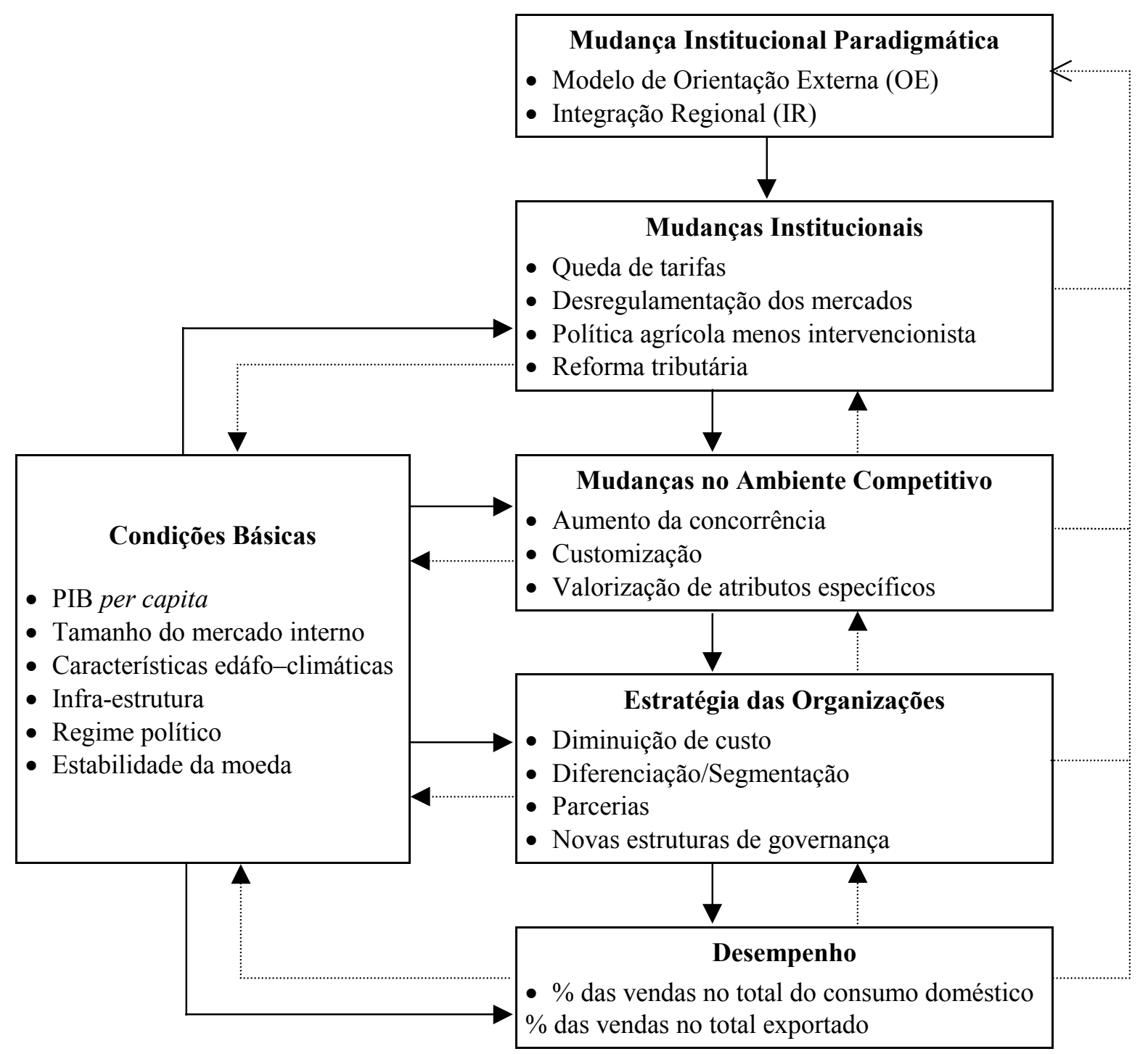

Figura 1 - Mudança Institucional e Desempenho.

internacional. Regras podem ter sido criadas com objetivo de induzir um determinado comportamento que não seja a eficiência em termo de desempenho.

As políticas agrícolas, notadamente dos países em desenvolvimento, envolvem não apenas a escolha de alocação eficientes, mas problemas distributivos intertemporais e entre grupos sociais. Segundo KRUEGER (1995:93-94), "a crença de que a industrialização era o último objetivo da política econômica foi também utilizada para argumentar (às vezes explicita- mente, mas mais freqüentemente de modo tácito) que os preços da alimentação da população urbana deveriam ser contidos por meio da intervenção na distribuição dos produtos agrícolas. Essa visão era fundamentada em parte em considerações sobre a distribuição de renda, uma vez que os preços da alimentação eram comprimidos com o objetivo explícito de ajudar a população urbana pobre".

As mudanças nas regras do jogo no Brasil e na Argentina, discutidas na próxima seção, estão associadas à transição entre as etapas de 
substituição de importação (SI) e de orientação externa (OE) nos dois países.

\section{Instituições no Brasil e na Argentina na Etapa SI}

$\mathrm{T}^{-}$ endo em vista o quadro teórico apresentado anteriormente, nessa seção serão abordados as principais regras que o modelo de SI determinou e as principais implicações em termo de desempenho nas culturas de milho e soja.

\section{(i) Brasil}

O fato de o Brasil ter uma grande população que necessita ser alimentada criou um certo consenso, tanto por parte dos consumidores como por parte dos responsáveis pela política agrícola, acerca da responsabilidade do governo de intervir para modernizar a agricultura brasileira, dando suporte ao processo de SI.

As regras de política agrícola esboçadas nesse período embutia a hipótese básica do chamado "modelo de difusão", que atribui um papel preponderante da tecnologia para $\mathrm{o}$ desenvolvimento da agricultura moderna. O mecanismo de transferência e propagação de tecnologia para as regiões e para os agricultores de baixa produtividade seria dado mediante subsídios aos denominados "insumos modernos" (MELO, 1980:13).

$\mathrm{O}$ modelo de incentivos à modernização incluía, entre outras medidas, o estímulo à mecanização, à adubação racional e orientada, ao uso de sementes selecionadas, à rotação de culturas, à irrigação e ao uso de defensivos. Para isso foi estruturado um amplo programa de política agrícola, com a instituição de importantes instrumentos, nos quais destacam-se: i) crédito rural subsidiado, com a instituição do Sistema Nacional de Crédito Rural (SNCR) Lei $\mathrm{n}^{\circ} 4.829$ de 1962 ; e ii) a política de garantia de preços mínimos (PGPM).

Quando de sua implantação, a política de garantia de preços mínimos (PGPM) perseguia três objetivos principais: i) garantir renda mínima aos produtores no período da safra, quando os preços tendem a diminuir muito; ii) reduzir a incerteza dos preços futuros; e iii) indicar os produtores, por meio de reajustes maiores (ou menores), quais as culturas que, de acordo com a avaliação do governo, deveriam ter a área aumentada (ou diminuída) naquela safra. $\mathrm{Na}$ medida que o preço mínimo atendia finalidades nem sempre compatíveis entre si, sua fixação tornava-se um processo complexo, além do que o governo também procurava evitar resultados indesejáveis, tais como a necessidade de adquirir parcela significativa da safra num determinado ano. Assim, a adoção simultânea de objetivos visando, de um lado, a garantia de renda ao produtor e, de outro, preços baixos dos alimentos ao consumidor, gerava incompatibilidade e distorções aos sistemas agroindustriais, principalmente dos ligados ao mercado interno. Já os que tinham dinâmica voltada ao mercado externo não havia esta incompatibilidade de forma que os incentivos para incremento da produtividade eram maiores.

$\mathrm{Na}$ prática, o programa de preços mínimos estava determinado pelo Conselho Deliberativo da Superintendência Nacional de Abastecimento (SUNAB), órgão criado com objetivo principal de evitar o descontrole dos preços no mercado interno, resguardando os interesses dos consumidores e das indústrias substitutas de importação. Com um amplo poder de intervir no mercado para controlar os preços e garantir o abastecimento no mercado nacional, eram prerrogativas da SUNAB controlar as margens de lucro, desapropriar estoques, proibir exportações, tabelar preços e realizar importações quando necessárias, pois o mercado estava protegido por barreiras tarifárias. Assim, priorizando os interesses dos consumidores urbanos e das indústrias, a política da SUNAB tinha muitas vezes uma dinâmica expressamente oposta à política de incentivos à modernização da produção agrícola. Particularmente nos períodos de recrudescimento da inflação, é reconhecido o sucesso da política da SUNAB na manutenção de preços baixos dos produtos de consumo doméstico (MELO, 1980 e LOPES, 1987). 
Os diferentes desempenhos dos sistemas brasileiros de milho - voltado para o mercado interno - e soja - voltado para o mercado externo - são amplamente conhecidos. O milho, além de ter sido preterido pela política agrícola nas décadas de 70 e 80 , é uma cultura doméstica em que as regras informais do mercado determinaram que sua produção fosse disseminada em todo o território nacional. Ou seja, tendo uma forte participação na dieta das populações mais pobres, o milho é produzido por uma parcela significativa de pequenos produtores de subsistência, o que está associado ao fato de que a produtividade da terra nessa cultura ainda se situa $40 \%$ abaixo da média mundial sendo a metade da Argentina. Naturalmente, a produtividade média deve ser vista com restrições, principalmente devido à grande heterogeneidade dos sistemas de produção de milho no Brasil. Há casos de produtores de alta tecnologia cuja produtividade está ao redor de $6 \mathrm{mil} \mathrm{kg} /$ hectare, quando a média brasileira é de 2,36 mil $\mathrm{kg} /$ hectare. Se as regras de política agrícola e formação de estoques oficiais resultaram em perda de competitividade para o segmento produtor de milho em termos de sistema agroindustrial (SAG) a pressão negativa sobre os preços da matéria-prima no curto e médio prazo foram particularmente propícias para o desenvolvimento dos segmentos de rações e da avicultura.

Já a soja ao longo das décadas de 60 e 70 recebeu grande parte das transferências do Estado para a agricultura e agroindústria, tendo o Brasil se tornado ainda na década de 70 , o segundo maior produtor mundial desse grão. Nos anos 80, quando os recursos do governo para custeio começaram a minguar, foi possível a criação de instrumentos privados alternativos. Os exportadores, incluindo as tradings, contaram com o ACC (Adiantamento de Contrato de Câmbio) para financiar suas operações, com custos inferiores ao do crédito doméstico, e puderam repassar parte dos recursos para os produtores por meio de contratos de "soja verde", que consistiam na venda antecipada da safra, com preços fixos (inicialmente em dólar americano), para entrega futura. Em algumas modalidades, mais comuns entre cooperativas e cooperados, os contratos de "soja verde" envolviam o adiantamento de insumos como sementes e fertilizantes contra a entrega futura de determinada quantidade do produto. Previa-se nesses contratos a quantidade do produto, a data e o local da entrega, além de outras especificações como maturação, teor de umidade, impurezas e percentual máximo de quebrados.

$\mathrm{O}$ desenvolvimento de novas tecnologias e sua difusão, no modelo agrícola dos anos 70, ficava a cargo do Estado, dadas as baixas taxas de acumulação do setor agrícola e a ausência de mecanismos para garantir a apropriabilidade do retorno dos investimentos em P\&D.

Até 1975 , toda a produção brasileira de soja era realizada com cultivares e técnicas importadas dos Estados Unidos, onde as condições climáticas e os solos são diferentes do Brasil. Assim, a soja só produzia bem, em escala comercial, nos estados do Sul, onde as cultivares americanas encontravam condições semelhantes a de seu país de origem. A criação de novas cultivares principalmente por parte da estatal Embrapa (Empresa Brasileira de Pesquisa Agropecuária) levou a soja para as regiões de clima tropical no Brasil (Centro-Oeste, Nordeste e Norte). A partir daí, inúmeras outras cultivares nacionais foram criadas para dar estabilidade ao cultivo de soja nas chamadas regiões de fronteira agrícola.

Apesar da importância marcante do estado no processo de $\mathrm{P} \& \mathrm{D}$ para a cultura da soja, a participação da iniciativa privada também é marcante. As indústrias de sementes, fertilizantes, defensivos e máquinas têm trazido tecnologias modernas para a cultura e, talvez o que seja mais importante, têm auxiliado na sua transferência para os produtores, em um contexto em que a extensão rural coordenada pelo Estado encontra-se desestruturada. Particularmente, a indústria de sementes, tanto nas fases de P\&D quanto de multiplicação, é considerada como "vetor de tecnologia" por ampliar o potencial produtivo das variedades, adaptá-las às condi- 
ções regionais e estimular o uso de insumos em níveis adequados.

\section{(ii) Argentina}

$\mathrm{Na}$ Argentina, assim como no Brasil, até o final dos anos 70 as instituições criadas na economia assentavam-se no modelo de substituição de importações, o que levou à criação de organismos especiais para a regulamentação do mercado agrícola (ORDOÑEZ, sd). Em 1936 foi instituída a Junta Nacional de Granos (JNC) Argentina, com as seguintes atribuições: i) regulamentação dos mercados (fixação de preços internos e de exportação, concretização das exportações e manutenção de estoques reguladores); ii) operacionalização de terminais e silos; iii) supervisão de funcionamento do mercado de grão entre outras (ESTEFANELL, 1997).

Em 1957 foi criado o Instituto de Nacional de Tecnologia Agrícola (INTA), que juntamente com outros organismos de ciência e tecnologia fundado pelo Estado (Comissão Nacional de Energia Atômica (CNEA), Conselho Nacional de Investigações Científicas e Técnicas (Conicet), Instituto Nacional de Tecnologia Industrial (INTI)), tinham por objetivo promover o desenvolvimento do país.

A criação do INTA se constituiu em um subproduto do diagnóstico da CEPAL (Comissão Econômica Para a América Latina) que argumentava estar o setor agrícola relativamente atrasado do restante da economia. Ao Estado, elemento central da modernização da economia, cabia a responsabilidade de criar e difundir tecnologia agrícola seguindo os exemplos de outros países mais adiantados, como Estados Unidos e Canadá.

Até os anos 70 o INTA teve uma participação importante no desenvolvimento de inovações tecnológicas para a agricultura, tanto no que diz respeito ao manejo agrícola como em pesquisas na área de híbridos de milho e sorgo e seleção em variedades de soja.

Um outro papel importante do Estado na política agrícola dos anos 60 e 70 foi o incentivo à mecanização, inicialmente com a participação direta na fabricação de tratores e mais tarde por medidas de fomento à indústria privada.

$\mathrm{Na}$ região dos Pampas o crescimento da produção foi acompanhado pelo rápido aumento da produtividade do trabalho. $\mathrm{O}$ incentivo à mecanização pode ser comprovado pelo subsídio implícito existente no crédito agrícola que flutuava entre a quarta parte e a metade do preço do trator, chegando até mesmo a representar 78\% em 1994.

A mecanização possibilitou solucionar o problema de escassez e encarecimento da mãode-obra no país, como também favoreceu a incorporação de inovações tecnológicas. Foi uma das condições que permitiu uma ampliação rápida da utilização de híbridos de milho e a difusão do cultivo da soja nos anos 70 .

A política adotada nesse período teve como resultado um desempenho excepcional da produção dos bens exportáveis da região pampeana, responsável por $95 \%$ da produção agrícola da Argentina. Nas principais culturas agrícolas - trigo, milho, soja, sorgo e girassol -, que representam $90 \%$ da produção da Argentina, entre 1960/61 e 1986/87 houve um incremento de 2,5 vezes, passando de 13 milhões para 32 milhões de toneladas.

Nos anos 70, ou seja, bem antes que o Brasil a Argentina inicia o processo de reestruturação econômica. A política de orientação liberal colocada em prática relegou o setor público, e o INTA em particular, a uma posição subsidiária no desenvolvimento de tecnologia para a agricultura. Com a liderança do setor privado nas inovações, houve um crescimento maior no número de projetos relacionados ao desenvolvimento de híbridos.

Foi também nesse período que o Estado passou a ter menos importância no financiamento do progresso tecnológico, ficando a responsabilidade com agentes privados: cooperativas, indústria, acopiadores (agentes que exercem um papel semelhante aos elevators americanos, no que se refere à originação de grãos na região produtora e à comercialização com as grandes indústrias exportadoras) e vendedores de insumos. 
O processo de reestruturação produtiva refletiu de um lado na estrutura agrária do país com a seleção de produtores segundo a capacidade de incorporar tecnologia. Esse processo resultou na concentração da produção com a expulsão de um número significativo de pequenos produtores. De outro lado, o início da reestruturação agrícola anterior ao processo brasileiro refletiu, entre outras coisas, um ingresso nos anos 90 com um diferencial de competitividade. Sendo a Argentina uma exportadora líquida de alimentos, com uma população bem inferior à brasileira, possibilitou a implantação de uma política agrícola com menor grau de interferência do Estado e mais competitiva, principalmente com relação à produção de milho.

Dessa forma, observa-se que, a partir dos anos 80 , as mudanças no ambiente institucional que ocorreu no Brasil e na Argentina estão associados à transição entre as subfases de IS e de EO e as condições básicas das economias desses dois países, tais como população, clima, fertilidade do solo, renda per capita, infraestrutura, regime político etc. Tanto as regras institucionais criadas para dar suporte ao modelo EO como as características básicas de cada economia vão implicar em termos de desempenho das culturas de milho e soja.

$\mathrm{Na}$ próxima seção serão examinados alguns aspectos relacionados à produtividade, logística e do setor agroindustrial no Brasil e Argentina e seu desempenho recente ao longo da última década.

\section{Desempenho nos Sistemas de Milho e Soja no Brasil e na Argentina}

\subsection{Condicionantes das Novas Regras na Etapa OE}

\section{(i) Brasil}

$\mathrm{N}^{\circ}$ final dos anos 80, com a crescente incapacidade do Estado brasileiro de financiar os mercados agrícolas, tornou-se clara a exaus- tão das regas institucionais adotadas até então. Os recursos do Tesouro Nacional destinados ao crédito rural, que eram de $80 \%$ do total do crédito rural concedido pelo Banco do Brasil, em 1985, caíram para $14 \%$ em 1990. As medidas anunciadas para execução dos planos de safras não eram cumpridas por falta de recursos. Os preços mínimos divulgados antes do plantio deixavam de ser honrados, embora o DecretoLei n. ${ }^{\circ} 79 / 66$ e as Leis n. ${ }^{\text {os }} 8.171$ e $8.174 / 91$ assegurassem preços mínimos para todos aqueles que produzissem produtos sujeito à PGPM. Somente na safra 94/95 a cobertura dessa medida foi restringida para um valor máximo para cada produtor.

Em 1988 com a Resolução n. ${ }^{\circ} 155$ do Conselho Nacional do Comércio Exterior (CONCEX) foram aprovadas medidas que visavam a liberalização do mercado externo para o milho, arroz, soja. Esse ato marcou o início da subfase de desenvolvimento orientado para o mercado externo, em contraposição ao modelo de substituição de importações. As exportações de arroz, milho, soja e algodão deixaram de estar sujeitas às restrições quantitativas e qualitativas, ficando, entretanto condicionada a um sistema de registro prévio de venda.

Em $1^{\circ}$ de janeiro de 1991 entrou em vigor a União Aduaneira entre os países membros do Mercosul e com isso a produção brasileira de milho perdeu competitividade em relação ao produto importado. A alíquota de importação do milho proveniente dos países do Mercosul foi zerada, ficando em $8 \%$ para o produto proveniente dos países não membros.

Seis anos mais tarde, depois de tentativas frustadas de estabilização da economia brasileira, foi implementado o Plano Real, que resultou na queda da inflação de um patamar de $25 \%$ ao mês entre 1989 e 1993 para 2,34\% em julho entre 1994 e 1995. O programa de estabilização procurou acelerar o processo de abertura, colocando as empresas nacionais em contato direto com o mercado internacional, e o de privatização, iniciado no final dos anos 80 . 
Estes marcos - a diminuição da intervenção do Estado nos mercados, abertura, estabilização e privatizações - são as principais mudanças das regras institucionais que passaram a nortear a reorganização e a competitividade dos grãos no Brasil e em particular a soja e o milho.

\section{(ii) Argentina}

$\mathrm{Na}$ Argentina também o tripé estabilização/desregulamentação/privatizações passou a ter papel fundamental na busca de um novo modelo de competitividade. A primeira importante mudança nas "regras do jogo" ocorreu em 1991 com o Plano de Estabilização de Cavallo, baseado fortemente na taxa de câmbio fixa. Assim, três anos antes que o Brasil, a economia Argentina foi estabilizada. Desde 1993, os índices de inflação anual têm se mantido na casa de um dígito, sendo que em 1997, essa taxa foi de $0,3 \%$.

De forma concomitante, o governo estabeleceu medidas de desregulamentação da economia e iniciou um forte processo de privatizações dos transportes e portos, que se refletiram em uma sensível diminuição de custos e aumento da eficiência, a partir de investimentos privados na modernização e ampliação de portos e ferrovias.

Uma outra medida importante refere-se à política de eliminação dos impostos de "retenciones" nas exportações. Nos anos 80, os exportadores de cereais pagavam de 20 a $30 \%$ nesta operação; em 1991, passaram a pagar 10\%, e atualmente, recebem reembolsos de 2,5\%. Apenas a soja em grão ainda paga um tributo de $3,5 \%$. Além disso, há um estímulo para a exportação de produtos manufaturados, que varia conforme o produto e vai desde $1,4 \%$ para os farelos até $6,8 \%$ para a exportação de óleos envasados. Finalmente, a redução das tarifas alfandegárias permitiu o expressivo aumento do consumo de fertilizantes e outros insumos.

$O$ processo de desregulamentação resultou na dissolução de dez organismos governamentais que regulavam diversas atividades do setor agroindustrial. O governo passou a atuar de forma menos intervencionista e mais ligada à definição de políticas e programas que estimulam a competitividade dos produtos e incentivam o desenvolvimento da indústria alimentícia e sua articulação com o setor primário.

Secretaria de Agricultura, Pecuária, Pesca e Alimentação (SAGPyA) passou a desenvolver programas de apoio ao setor, sem intervir diretamente na economia. Suas principais funções podem ser descritas como: i) promoção de negócios - tais como a promoção de produtos em mercados externos; ii) participação no controle sanitário e de qualidade (exercido pelo Serviço Nacional de Sanidade e Qualidade Agroalimentar - SENASA); iii) provisão de informações oficiais; iv) constituição de mecanismo de garantia; v) supervisão de mercados, para evitar manipulações dos preços na Câmara Arbrital e Bolsas de Futuros; e vi) a identificação de setores com potencial exportador.

Um importante programa para a modernização do setor de grãos refere-se ao "Comerciar", que fomenta a utilização de mecanismo de gerenciamentos de riscos como os Mercados de Futuros e de Opções pelos produtores, por meio de cursos nas regiões produtoras. Há, também, o estímulo para formas alternativas de financiamento, como os warrants, cuja utilização cresceu mais de 10 vezes entre 1993 e 1997 e movimentou mais de 1 bilhão de dólares nesse último ano apenas para produtos agropecuários, segundo o programa.

Realmente, o fim da inflação, que permitia ganhos financeiros independentemente da eficiência dos agentes do mercado, e com a conscientização maior da necessidade de gerenciamento de riscos, a Bolsa de Futuros de Buenos Aires - MAT - tem aumentado sistematicamente o volume de contratos negociados a partir do início da década. Enquanto em 1990, foram negociados pouco mais de 1 milhão de toneladas de grãos nos mercados futuros, em 1997, esse volume foi superior a 20 milhões, considerando os contratos de futuros e de opções, o que representa quase $40 \%$ do total de 
grãos produzido no país. Para efeito de comparação, no Brasil, os volumes negociados de soja e milho na Bolsa de Mercadorias e Futuros $\mathrm{BM} \& \mathrm{~F}$ - ainda não ultrapassam os $2 \%$ da produção física no país.

\subsection{Desempenho Recente: Brasil e Argentina}

Esta seção examina alguns aspectos de produtividade, de logística e do setor agroindustrial no Brasil e Argentina e seu desempenho recente ao longo da última década.

\subsubsection{Aspectos da Produção Rural}

O crescimento da produção de grãos na Argentina tem superado até mesmo as previsões mais otimistas, visto que, considerando-se apenas as últimas cinco safras, o seu crescimento total foi de 55\%. A maior parte deste aumento deveu-se à incorporação de novas áreas - antes utilizadas preferencialmente para pastagens -, com um aumento médio anual de $7 \%$ na área plantada neste período. Os ganhos de produtividade também contribuíram para o desempenho da produção, apresentando uma taxa de crescimento média de $3 \%$ ao ano.

Acredita-se que os elevados preços internacionais exerceram um papel fundamental para o estímulo do aumento da área de plantio na

Argentina. Realmente, considerando os principais grãos produzidos pode-se constatar a relação direta entre o aumento da média dos preços internacionais e o aumento da área plantada daqueles produtos no mesmo ano. A forte inserção que o país passa a ter no mercado internacional, principalmente a partir do plano de conversão e implantação do Mercosul estimula, então, o crescimento e a rápida restruturação do setor.

No Brasil, percebe-se também um aumento significativo da produção dos principais grãos desde o início da década. Considerando-se o milho e a soja, que representam mais de $80 \%$ da produção de grãos do país, contata-se crescimentos superiores a 5\% ao ano, crescimento este em função basicamente da produtividade, visto que o aumento da área nesta década foi praticamente nulo.

Os Gráficos 1 a 4 mostram a evolução da produção e área do milho e soja no Brasil e na Argentina, desde o início da década.

Quanto à produtividade, percebe-se em ambos os países um significativo aumento na tecnologia utilizada para a produção de grãos. $\mathrm{Na}$ Argentina, a idéia de que a sua competitividade estaria centrada única e exclusivamente em seus solos férteis não mais se sustenta e a conscientização do inevitável esgotamento dessa fertilidade aliada a uma maior capitalização do setor possibilita um grande incremento na utilização de insumos modernos.

Assim, segundo a SAGPyA, constata-se que o consumo de fertilizantes quintuplicou desde o início dos anos 90 e a utilização de agroquímicos aumentou em 180\% nos últimos seis anos. Do total dos fertilizantes utilizados no país, cerca de $40 \%$ é utilizado na produção de trigo e $20 \%$ no milho. No entanto, apesar desse incremento, o consumo de nutrientes por área na Argentina ainda representa menos de $30 \%$ da média mundial e 40\% da média na América Latina.

Outras importantes alterações nos sistemas de produção argentinos também são observadas, como a maior utilização de plantio direto ou cultivo mínimo, utilização de novas variedades (com maior potencial de produtividade e de qualidade) e utilização de materiais transgênicos (como a soja resistente a Roundup e milho BT). Estima-se que já se utiliza cerca de $70 \%$ de soja geneticamente modificada no país e $30 \%$ de milho transgênico.

No Brasil, a heterogeneidade dos sistemas produtivos, principalmente no caso do milho, reduz substancialmente a produtividade média no Brasil. Isto faz, no entanto, com que as margens para o aumento dos rendimentos sejam mais elevadas no Brasil do que na Argentina, na medida em que se constata um significativo aumento da produção comercial do milho. No caso da soja, praticamente não há grandes diferenças de produtividade entre os dois países. 


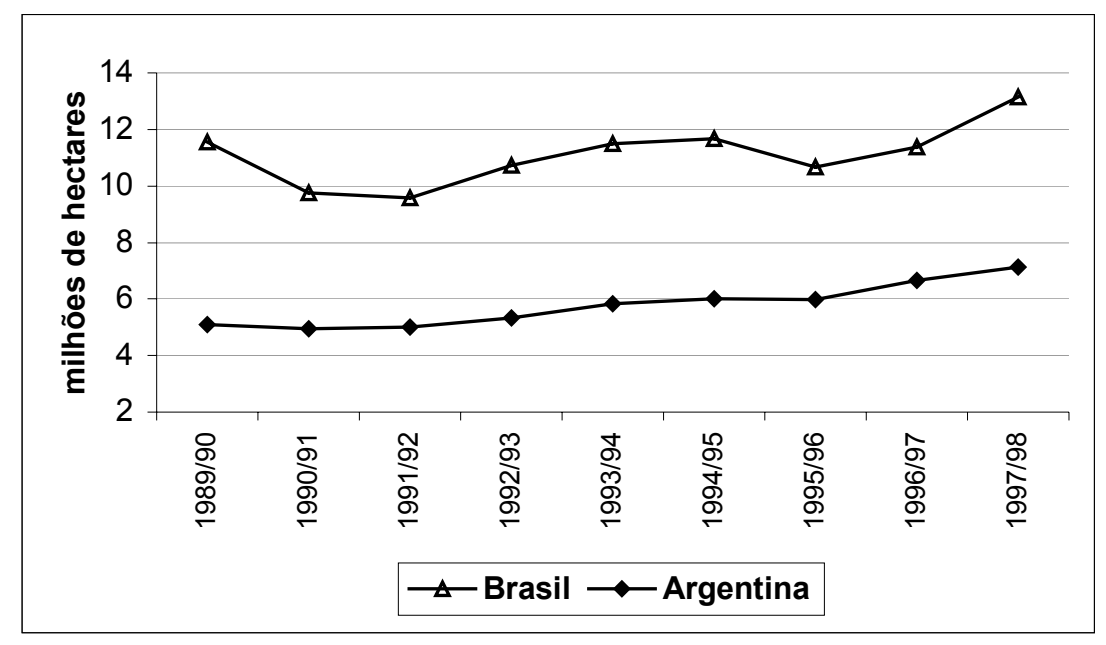

Gráfico 1 - Evolução da área plantada de soja no Brasil e na Argentina, em milhões de hectares, 1990 a 1998.

Fonte: Secretaria de Agricultura, Ganadería, Pesca y Alimentación - SAGPyA - da Argentina e CONAB.

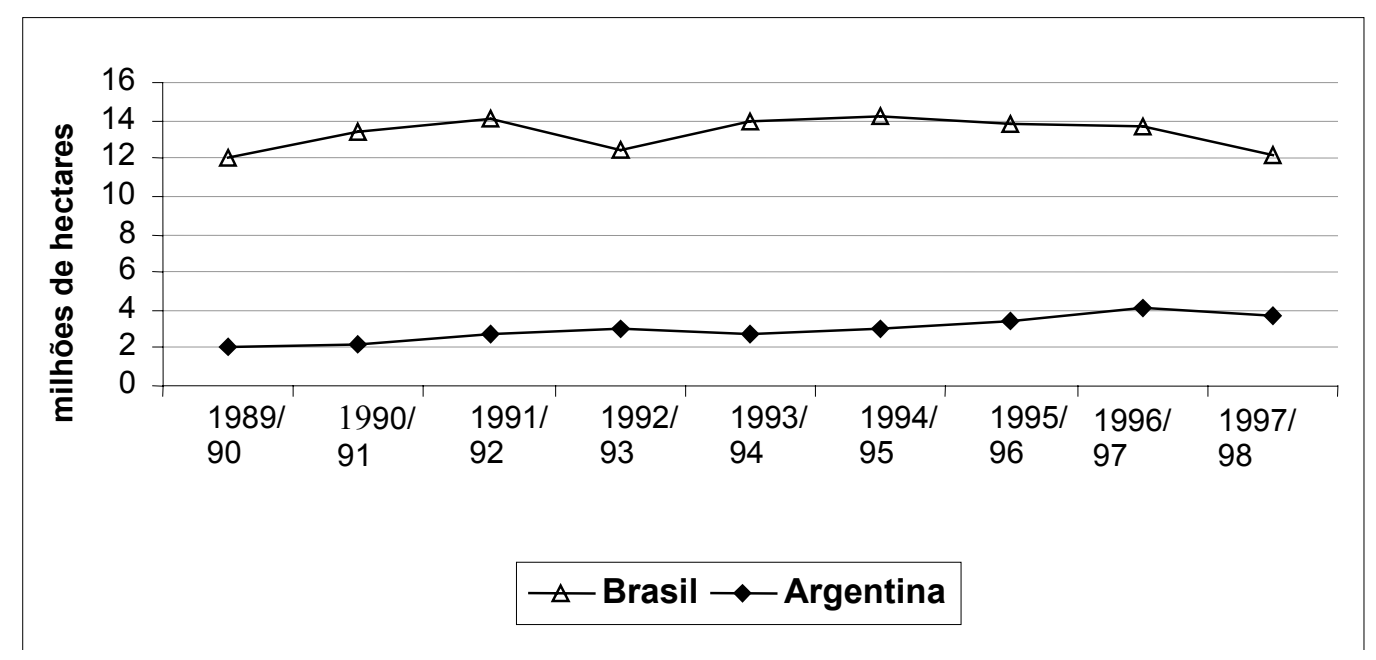

Gráfico 2 - Evolução da área plantada de milho no Brasil e na Argentina, em milhões de hectares, 1990 a 1998.

Fonte: Secretaria de Agricultura, Ganadería, Pesca y Alimentación - SAGPyA - da Argentina e CONAB.

Os Gráficos 5 e 6 comparam a produtividade média da soja entre a Argentina e o Brasil. Podese observar que a produtividade argentina se assemelha à brasileira no caso da soja, porém ainda é $60 \%$ superior à média brasileira no caso do milho. Vale observar que a queda da produtividade do milho em 1995/96 e da soja em
1996/97 deve-se a seca que atingiu as regiões produtoras de Santa Fé e Córdoba (Gazeta Mercantil, 30 de maio de 1997).

No que tange à distribuição geográfica, diferentemente do Brasil, onde a produção de grãos apresenta uma grande dispersão e elevada heterogeneidade quanto aos sistemas produtivos, 


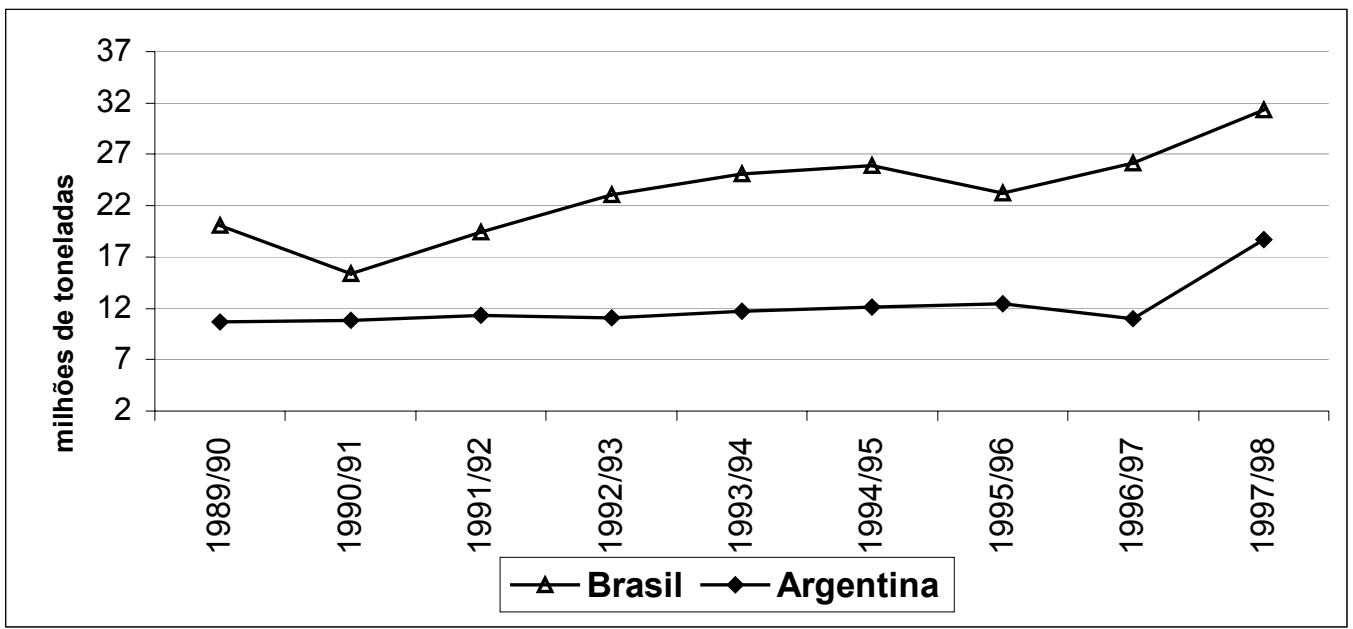

Gráfico 3 - Produção de soja no Brasil e na Argentina, em milhões de toneladas, 1990 a 1998. Fonte: Secretaria de Agricultura, Ganadería, Pesca y Alimentación - SAGPyA - da Argentina e CONAB.

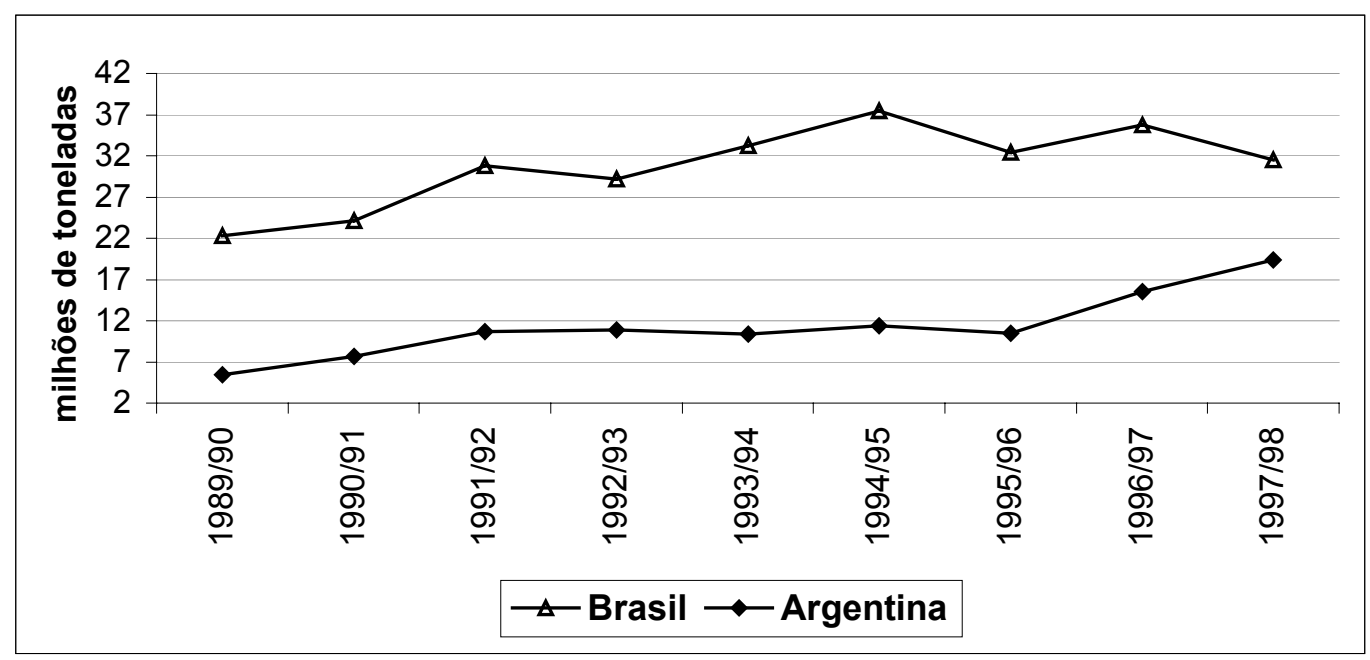

Gráfico 4 - Produção de milho no Brasil e na Argentina, em milhões de toneladas, 1990 a 1998. Fonte: Secretaria de Agricultura, Ganadería, Pesca y Alimentación - SAGPyA - da Argentina e CONAB.

a produção de cereais e oleaginosas na Argentina ocorre principalmente na região dos pampas, que se caracteriza por apresentar excelente qualidade de solos e condições climáticas ideais, com índices pluviométricos da ordem de 800 $\mathrm{mm} / \mathrm{ano}$. Há também uma maior homogeneidade quanto aos sistemas produtivos, diminuindo a dispersão da produtividade média.

\subsubsection{Aspectos de Logística}

O destino da quase totalidade da produção na Argentina é os terminais portuários para exportação, onde se localiza também a maior parte da indústria processadora. Essa concentração geográfica da produção e do seu destino possibilita uma maior eficiência no planejamento logístico, permitindo preços médios de fretes significativamente inferiores aos brasileiros. 


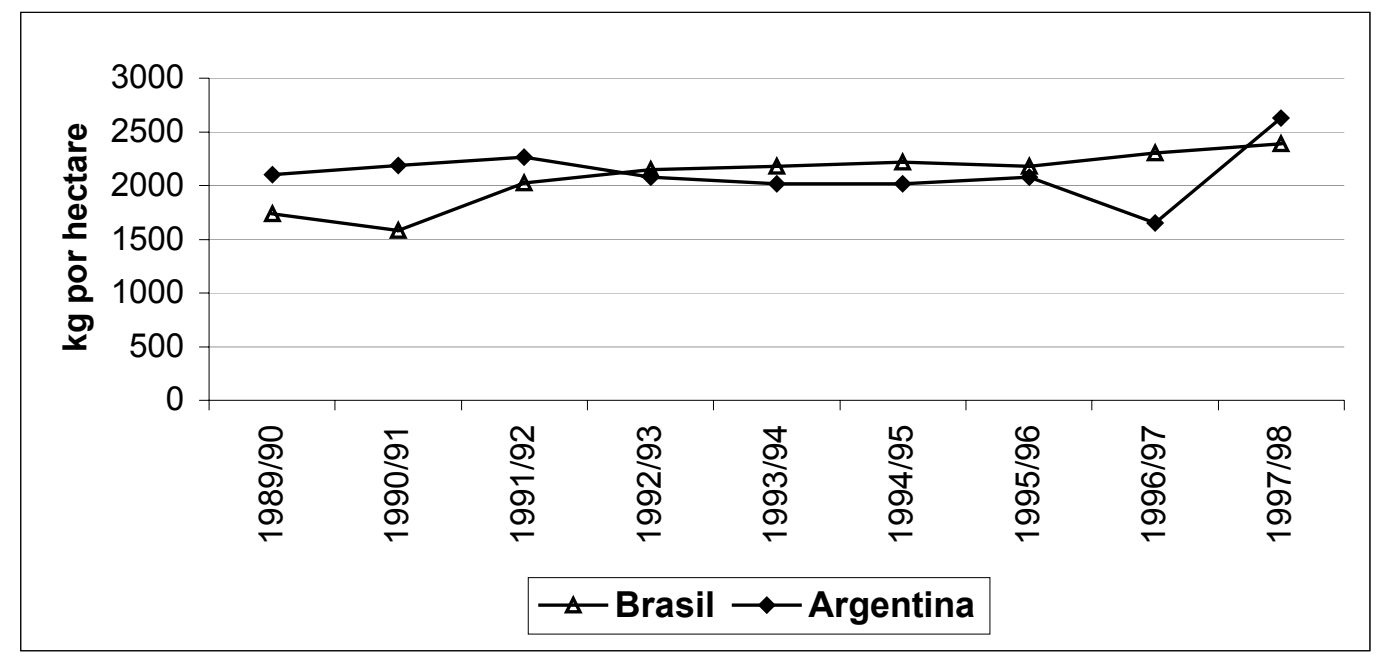

Gráfico 5 - Produtividade de soja no Brasil e na Argentina, kg por hectare, 1990 a 1998. Fonte: Secretaria de Agricultura, Ganadería, Pesca y Alimentación - SAGPyA - da Argentina e CONAB.

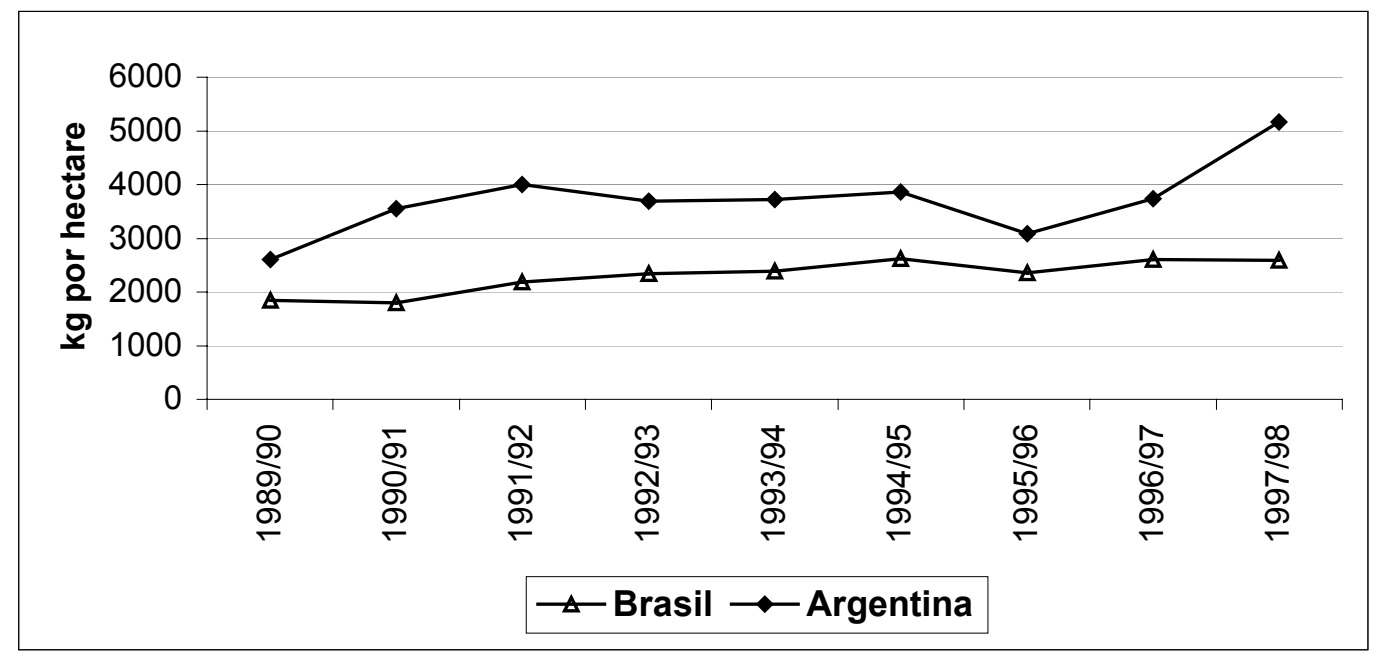

Gráfico 6 - Produtividade de milho kg por hectare entre 1990 e 1998.

Fonte: Secretaria de Agricultura, Ganadería, Pesca y Alimentación - SAGPyA - da Argentina e CONAB.

Apenas para se ter uma idéia do nível de concentração geográfica, a região produtora mais distante dos portos situa-se a cerca de $400 \mathrm{~km}$ dos portos. Segundo a SAGPyA, seu frete pode custar, no período de safra, US\$ 18,00/t. A média do custo do frete rodoviário de grãos no país, no entanto, gira em torno de US\$10,00/t.

No Brasil, os percursos chegam a atingir distâncias de $1.500 \mathrm{~km}$ para a soja, ou ainda maiores para o milho. Um frete da região do Sudoeste de Goiás para o Porto de Santos, por exemplo - em torno de $800 \mathrm{~km}$ - chega a custar mais de US\$ 40,00/t durante o período de safra. Segundo um levantamento realizado pelo SIFRECA/ESALQ/USP, o impacto do custo do transporte da soja e do milho no Brasil é bastante elevado, representando cerca de, respectivamente, $16 \%$ e $23 \%$ sobre o seu preço médio. 
Quadro 2 - Matriz de transporte de grão no Brasil e Argentina. Fonte: Bolsa de Rosário e Conab.

\begin{tabular}{|l|c|c|c|}
\hline & Rodoviário & Ferroviário & Hidroviário \\
\hline - Argentina & $80 \%$ & $19 \%$ & $1 \%$ \\
\hline - Brasil & $82 \%$ & $16 \%$ & $2 \%$ \\
\hline
\end{tabular}

Segundo estimativas do Boletim da Bolsa de Comércio de Rosário ( $\mathrm{n}^{\circ}$ 817, dezembro de 97), na Argentina, no ano de 1997, foram efetivamente comercializadas 47,5 milhões de toneladas de grãos, sendo que 38 milhões de toneladas foram transportados por caminhões, 9 milhões por ferrovia e cerca de 500 mil toneladas, por via fluvial, ou seja, respectivamente $80 \%, 19 \%$ e $1 \%$ do total comercializado. Essa distribuição é semelhante à atual matriz de transporte de grãos no Brasil, que transporta, respectivamente, $82 \%, 16 \%$ e $2 \%$, pelos modais rodoviário, ferroviário e hidroviário, porém acredita-se que com as recentes privatizações das ferrovias na Argentina, possa haver uma melhoria nesse serviço e aumento na utilização do transporte ferroviário no curto prazo.

No Brasil, esse processo de transformação deve ser ainda maior. No início da década de 80 houve um processo de ocupação dos cerrados, que atualmente já respondem por quase $40 \%$ da produção de grãos no país. Esta migração ocorreu principalmente em função dos incentivos governamentais. Com a diminuição desses incentivos e a maior abertura comercial, ficaram mais aparentes os problemas de competitividade dos grãos produzidos no Centro-Oeste em função dos elevados custos de transportes e a despeito das elevadas produtividades obtidas naquela região. Dessa forma, diversos investimento em novos corredores de escoamento de grãos estão sendo realizado, o que deve gerar uma nova dinâmica na produção e industrialização de grãos no país.

Finalmente, um dos aspectos que mais tem contribuído para a competitividade das exportações argentinas refere-se à diminuição dos custos portuários após o processo de privatização e desre- gulamentação dos serviços. Atualmente, esse custo se situa em torno de US\$2,50 a US\$3,00/t, contra valores entre US $\$ 8,00$ e US\$10,00/t no Brasil (SOUSA \& MARQUES, 1998).

\subsubsection{Aspectos do Setor Agroindustrial}

A indústria esmagadora de soja é, sem dúvida, um dos setores mais dinâmicos da agroindústria brasileira e argentina. Uma característica comum a ambas as indústrias dos dois países refere-se ao elevado índice de ociosidade.

No Brasil, a capacidade estática gira em torno de 30 milhões de toneladas, sendo esmagados cerca de 18 milhões de toneladas ao ano, o que representa uma ociosidade de cerca de $40 \%$. Na Argentina, a ociosidade é ainda maior. Atualmente, apresenta uma capacidade estática de 26 milhões de toneladas, porém esmaga cerca de 14 milhões de toneladas por ano e exporta o restante sob a forma de grão, menos de $10 \%$ de sua produção. Dessa forma, apresenta uma ociosidade de cerca de $50 \%$. No entanto, duas características principais distinguem a indústria argentina da brasileira: a primeira refere-se ao nível de concentração regional da indústria argentina e a segunda, à capacidade unitária de suas plantas (LAZZARINE \& NUNES, 1998).

Enquanto na Argentina, a indústria se concentra principalmente ao redor do Porto de Rosário, o Brasil apresenta uma dispersão geográfica bem maior. Assim, apesar de quase $60 \%$ da capacidade de esmagamento da soja brasileira se localizar nos três estados da região Sul do país, na última década passa a haver uma migração de parte do parque industrial para a região Centro-Oeste que atualmente representa mais de $20 \%$ do total da capacidade estática. No caso argentino, somente na região do complexo 
portuário de Rosário se concentra uma capacidade de esmagamento de cerca de $70 \%$.

Além disso, o Brasil apresenta também uma desvantagem quanto ao nível de escala das plantas de esmagamento. Na Argentina quase $80 \%$ da capacidade total refere-se a plantas de escala superior a $1.500 \mathrm{t} /$ dia, contra $55 \%$ no Brasil, além do que a capacidade das maiores não ultrapassa a média de 2.500 a $3.000 \mathrm{t} /$ dia. $\mathrm{Na}$ Argentina, a média situa-se em torno de 5.000 $\mathrm{t} / \mathrm{dia}$, sendo que existem várias plantas com capacidade superior a $7.000 \mathrm{t} / \mathrm{dia}$, como é o caso da Cargill (7.500 t/dia), Vicentín (9.200 t/dia) e Dreyfuss que apresenta uma surpreendente capacidade de $12.000 \mathrm{t} / \mathrm{dia}$.

Finalmente, ainda pode-se apontar duas importantes vantagens competitivas da indústria de soja argentina frente à brasileira: i) seus custos de esmagamento, que se situam em torno de US\$ 10,00/tonelada, podendo chegar a US\$ 7,00 em alguns casos, contra um custo médio de cerca de US\$ 15,00/tonelada no Brasil, situação fortemente vinculada às escalas industriais, e ii) a política de ressarcimento dos impostos indiretos incidentes na matéria-prima nas exportações argentinas, que são beneficiadas pelo mecanismo denominado "reintegro". Assim, são restituídos pelo governo argentino, entre 1,4 a $6,8 \%$ do produto industrializado exportado, dependendo do nível de industrialização do produto. Para o óleo bruto, o reembolso é de $1,4 \%$; para o óleo refinado, há um reembolso de $3,4 \%$ e, para o óleo refinado e envasado em embalagens de até 5 litros, o percentual é de $6,8 \%$ do valor do produto.

Deve-se destacar, no entanto, que a indústria brasileira de soja é mais diversificada e, nem sempre adota estratégias que priorizam apenas liderança em custos, visando única e exclusivamente economias de escala, como no caso da Argentina, cujo modelo baseia-se em produção de commodities - farelo e óleo - para a exportação. No caso brasileiro, existe uma expressiva parcela do setor industrial que busca também uma liderança em diferenciação de produtos e segmentação de mercados, que priorizam investimentos em marketing e inovação de produtos - visando, portanto, a qualidade - e seu cliente normalmente é o varejo ou atacado.

Quanto à indústria de milho na Argentina, esta ainda é pouco desenvolvida, sendo que $70 \%$ do total é exportado sob a forma de grãos. No Brasil, a produção é integralmente consumida no país, principalmente pelo setor de aves e suínos, que representa mais de $60 \%$ da demanda total. Assim, conforme discutido no item sobre o ambiente institucional, as regras de política de estoques oficiais são apontadas como um importante instrumento de regulação de estoques garantindo o desenvolvimento dessa indústria até o início dos anos 80. A partir daí, começam a se desenvolver relações de parcerias entre a indústria e avicultores resultando em um sistema bastante competitivo, tornando o Brasil atualmente o terceiro maior exportador de frango.

\section{Considerações Finais}

$\mathrm{O}$ desempenho dos sistemas agroindustriais do milho e da soja no Brasil e Argentina refletem as relações entre o ambiente institucional e competitivo de cada um desses países, que por sua vez foram condicionados pelas características básicas de cada um deles.

As regras de política agrícola no Brasil tiveram que levar em conta o grande contigente populacional que não pode depender exclusivamente de importações. Comparando Brasil e Argentina, verificou-se que a política agrícola brasileira expôs menos a produção nacional de produtos voltados ao mercado interno, o que de certa forma determinou um menor desempenho desse setor comparativamente ao de produtos voltados ao mercado externo. Na Argentina, não houve essa separação devido à menor necessidade de oferta interna de alimentos.

Entretanto, partindo de pontos diferentes, a Argentina que já tinha um maior grau de abertura em relação aos mercados internacionais, pode mais facilmente implementar ações visando a privatização e a desregulamentação dos 
serviços portuários, com a subseqüente redução dos custos incorridos na exportação de grãos. No Brasil, esse processo tem sido lento e tem apresentado resultados heterogêneos. A pesquisa de cultivares tropicais de soja adaptados às áreas de cerrados, em grande parte liderada por órgãos públicos, permitiu a expansão ainda em andamento da cultura. Por outro lado, a Argentina já está introduzindo cultivares transgênicas enquanto o Brasil ainda não tem uma posição sobre o cultivo e a comercialização de organismos geneticamente modificados.
A favor do Brasil está a possibilidade de investimentos na infra-estrutura logística, dos quais alguns já vem sendo realizados, acelerarem a redução dos custos, ao passo que na Argentina os ganhos com tais investimentos são apenas marginais. É de se ressaltar que nos dois países, apesar das diferentes vantagens competitivas de cada um, as mudanças institucionais que vieram se concretizando a partir de fins da década de 80 foram favoráveis ao crescimento da produção de milho e soja, com impactos positivos nos demais Segmentos dos respectivos sistemas agroindustriais.

\title{
Referências Bibliográficas
}

ESTEFANELL, G.A. (editor): El Setor Agroalimentar Argentino en los anos 90'. Buenos Aires - R. Argentina, IICA, 1997.

FARINA, E.M.M.Q.; AVEZEDO, P.F. \& SAES, M.S.M.: Competitividade: Mercado, Estado e Organizações, São Paulo, Fapesp/Singular/Pensa, 1997.

KRUEGER, A.O.: Political Economy of Policy Reform in Developing Countries. Cambridge, MA, London England, 1995.

LAZZARINI, S.G. \& NUNES, R.: "Competitividade do Sistema Agroindustrial da Soja". In: FARINA, E.M.M.Q. et al. Competitividade dos Sistemas Agroindustriais. IPEA, Brasília, 1998.
LOPES, M.R.: "Alguns Efeitos das Políticas Agrícolas Sobre o Progresso Técnico na Agricultura". Companhia de Financiamento da Produção, Carta Mensal da SUPEC, Ano III, n. ${ }^{\circ}$ 8, 1987.

MELO, F.B.H.: “A Economia Política dos Preços de Alimentos no Brasil". Trabalho para Discussão $n^{\circ} 34, \mathrm{FEA} / \mathrm{IPE} / \mathrm{USP}$, janeiro de 1980.

ORDOÑEZ, H.: El Rol del Estado y las Tres Argentinas los Cambios en las Politicas Publicas y de Agronegocios, Argentina, Ensayo, s.d.

SOUSA, E.L.L. \& MARQUES, P.V.: "O Modelo Agroexportador de grãos da Argentina”. Preços Agrícolas, n.144, Piracicaba, out. 1998.

\section{INSTITUTIONAL CHANGES AND THE PERFORMANCE OF THE PRODUCTION OF SOY AND CORN IN BRAZIL AND ARGENTINA}

\begin{abstract}
This paper examines the role of the institutions that affected Brazilian and Argentinean grain agroindustrial systems in this decade, using the New Institutional Economics as theoretical reference. Important differences mark the performance of the production of grains in these countries, despite Brazil and Argentina having followed the same model of development based on the process of import substitution and a closed economy. In addition to the edapho-climatic factor which brings initial advantages to the production of grains in Argentina, in general, this country has always had greater insertion in the international market due to its smaller population. The changes in the institutional environment and its effects on the recent performance of soybean and corn production in Brazil and Argentina are the objective of this work.
\end{abstract}


Key words: grains: corn and soybean, institutional changes, organizations, institutions, competitive strategies, import substitution, external orientation, agricultural policy. 